\title{
Legal Responsibility and Scalar Causation
}

DOI:

10.5235/20403313.4.1.102

\section{Document Version}

Accepted author manuscript

Link to publication record in Manchester Research Explorer

\section{Citation for published version (APA):}

Beebee, H. (2013). Legal Responsibility and Scalar Causation. Jurisprudence, 4(1), 102-108.

https://doi.org/10.5235/20403313.4.1.102

\section{Published in:}

Jurisprudence

\section{Citing this paper}

Please note that where the full-text provided on Manchester Research Explorer is the Author Accepted Manuscript or Proof version this may differ from the final Published version. If citing, it is advised that you check and use the publisher's definitive version.

\section{General rights}

Copyright and moral rights for the publications made accessible in the Research Explorer are retained by the authors and/or other copyright owners and it is a condition of accessing publications that users recognise and abide by the legal requirements associated with these rights.

\section{Takedown policy}

If you believe that this document breaches copyright please refer to the University of Manchester's Takedown Procedures [http://man.ac.uk/04Y6Bo] or contact uml.scholarlycommunications@manchester.ac.uk providing relevant details, so we can investigate your claim.

\section{open 2 Access}




\section{LEGAL RESPONSIBILITY AND SCALAR CAUSATION}

Helen Beebee

Please do not cite this version. The published version is: 'Legal Responsibility and Scalar Causation', Jurisprudence, 4 (2013): 102-8 (part of a review symposium on Michael Moore's Causation and Responsibility).

\section{Introduction}

In Causation and Responsibility, Michael Moore investigates the presuppositions about the metaphysics of causation that underpin legal doctrine. His basic position is that insofar as the law deploys causal concepts as a means of determining liability, it ought to refer to a real, mind-independent, objective relation. Hence, for example, legal questions that turn on the distinction between a proximate cause and a mere cause-in-fact, or between an intervening and a non-intervening cause, will only make sense if, or insofar as, there is some viable metaphysical account of causation that respects those distinctions. If there is no such account to be had, we should not retreat to a broadly Legal Realist position, according to which locutions such as 'proximate cause' and 'intervening cause' are regarded as self-standing legal locutions whose meaning is determined by moral or policy-driven concerns, independently of metaphysical considerations. Instead, either a different, non-causal basis for legal liability must be found, or else the legal doctrines in which such locutions are enshrined should be substantially altered in such a way that they make metaphysical sense in the light of our best theory about the true nature of causation.

In this paper, I shall focus on one alleged feature of causation - 'scalarity' which Moore uses to perform several key legal roles, as outlined in $\S 2$. However, I shall argue in \$3 that when it comes to scalarity, his aim of placing the causal doctrines required by the law on solid metaphysical foundations has not been met.

\section{What work is scalarity supposed to do?}

It is helpful to begin by distinguishing between two dimensions along which causation might (and, according to Moore, does) come in degrees, both of which 
Moore subsumes under the heading of scalarity, which I'll call limited transitivity and Degrees of influence:

Limited transitivity: Causation 'peters out' over time or " "tires" through its links' (102). Thus even if Caesar's crossing the Rubicon is a 'necessary condition for your loss of business on a given occasion, ... that event will compete poorly with another, more proximate event, such as my breach of contract by revealing trade secrets, as a cause of that loss. The sheer size of Caesar's contribution disqualifies Caesar's act as a cause' (398). Moore proposes that 'the strength of causation [diminishes] in proportion to the number of events through which it is transmitted' (122-3), so that what disqualifies Caesar's act as a cause of your loss of business is not merely the fact that it happened too long ago, but that there are too many intermediate events in the chain or process that connects the two events.

Degrees of influence: Two events can contribute to a given effect to different degrees even when they are temporally close together and so are roughly on a par in the limited transitivity sense. For example, '[i]f two defendants each strike a victim, who dies of the loss of blood, it seems to make sense to say that the blow that caused a greater loss of blood was more of a cause of death than the blow that resulted in a smaller loss of blood' (275-6).

With these two notions of scalarity in place, we are in a position to see what role Moore takes scalarity to play in the law. First, we have the concept of causal apportionment. In the case of tort law, Moore notes that '[o]nly in the product-misuse area of strict liability has explicit comparative causation gained much of a foothold'; but he also notes that in fact courts 'smuggle in notions of causal apportionment' in other ways too, namely via the notions of 'divisible harm' and comparative fault (118-9). Clearly causal apportionment requires scalarity in the degrees-of-influence sense (and perhaps also in the limited-transitivity sense).

Causal apportionment is a place where the law already appeals to scalarity an appeal that Moore apparently endorses. However, he also argues that scalarity can be put to work elsewhere, where the law's presuppositions about causation are mistaken. In particular, he argues (correctly in my view) that there is no genuine metaphysical distinction between a proximate cause and a mere cause-in-fact (or, 
relatedly, between a 'de minimis' cause and a 'substantial factor'), or between an intervening and a non-intervening cause (Ch. 12).

In the case of proximate causation, Moore says that 'no area of the law traces causal responsibility indefinitely ... Our liability doctrines thus presuppose that causation is the kind of relation that can "peter out" '(121). Consider, for example, Moore's streetcar case (122), where the driver speeds recklessly early on in his journey, thus arriving at a place where a tree falls - which injures a passenger earlier than he would have done had he not been speeding earlier. On Moore's view, the judgement that the speeding is too remote a cause of the injury to count as a legal cause is vindicated by the fact that there are too many events in the causal chain linking the two: the causal connection between the speeding and the injury has 'petered out' sufficiently for the driver's negligent act not to count as a proximate cause. Hence, while there is no hard-and-fast boundary between proximate and nonproximate causes, there is a vague boundary between those factors that are close enough to the effect to count as proximate causes and those factors that are too far away to count for legal purposes.

Moore also deploys limited transitivity as an approximate replacement for intervening causation. Given that there is no such thing as intervening causation, we can appeal to limited transitivity to explain why voluntary acts and other so-called intervening causes diminish the responsibility of previous acts of other agents. 'My own suggestion', he says, 'is that what the law uses here is simply sheer numbers of events that intervene between the defendant's act and the harm. None of these events need itself be an intervening cause as the law defines that phrase; rather, when there are too many event-links in the causal chain, it becomes too attenuated to support judgements of transitivity' (122).

Finally, Moore holds that the scalarity of causation should be deployed in the area of accomplice liability. He argues that in certain kinds of case - in particular those involving prior-acting accomplices - accomplice liability is not a sui generis, non-causal kind of liability, but (like principal liability) has a causal basis. In such cases the difference between accomplice and principal liability is thus a difference in degree rather than kind. The motivation for thinking of accomplice liability as noncausal comes from the doctrine of intervening causes: a prior-acting accomplice cannot be a proximate cause of a crime because the act of the principal will itself be an intervening cause of the crime and so will 'break the causal chain' between the 
accomplice's act and the crime. Once we abandon intervening causes as a metaphysical category, however, there is no bar to holding that the prior-acting accomplice is causally responsible for the crime: '[w] hatever is a sufficient causal contribution for liability as a principal ... should be sufficient for liability as an accomplice, and vice versa' (302). Nonetheless, prior-acting accomplices will often (but not always) bear less causal responsibility than principals, and this is because of scalarity. Generally (but not always), a prior-acting accomplice will contribute less in the degree-of-influence sense (the defendant who lures the victim to a deserted alley is less of a cause of the crime than the one who shoots the victim), and also (always) in the limited-transitivity sense, since there are more events between the accomplice's act and the crime than between the principal's act and the crime.

\section{Is causation really scalar?}

In this section, I shall argue that, in the case of limited transitivity, Moore's suggested measure of scalarity - the number of events in the chain between cause and effect fails. Moreover, there are good reasons to think that no measure will succeed in capturing either our ordinary intuitions or uncontroversial legal judgements concerning the extent to which causation 'peters out' over time. In the case of degrees of influence, Moore offers no measure at all - and so he fails to deliver any prospect of a practically useable metaphysical conception of this kind of scalarity. Overall, then, when it comes to scalarity Moore fails to deliver what he promises: a secure metaphysical foundation for those legal distinctions that do, or in his view should, appeal to scalarity.

The first point to be made is that Moore offers very little by way of motivation or argument for the claim that causation is scalar. He advertises an argument for scalarity (71, fn117) but I cannot find one in the advertised place (viz, Chapters 5 and 6). What we do find is in the advertised place is a description of the ways in which the law in fact appeals to scalarity, in both senses identified above. But in neither case does Moore address the question whether the presupposition that causation is scalar is metaphysically viable. All we are really offered by way of an argument is an appeal to common-sense intuitions, as with the Caesar and blood loss cases described in $§ 2$ above.

Let's start with limited transitivity. My first worry here is that, while we may agree with Moore about Caesar's crossing of the Rubicon, it seems that there are very 
many cases where we do not regard causation as 'petering out' over even very long periods of time (and with plenty of intermediate events). It is commonplace to talk about the contemporary effects of the British colonisation of Australia, or the Industrial Revolution, or the Second World War. I have never heard anyone suggest that these events simply happened too long ago - or that there have been too many events in the chain from, say, the Industrial Revolution and what happened in $2010-$ for it to be possible for such past events to have any effects on what happened in 2010.

Thus, I claim, our common-sense intuitions do not consistently support limited transitivity. And this leads me to my second worry, which is that, while it is possible to make relative judgements about the petering-out of causal influence within a single case, it is unclear that a 'measure' of petering-out is in principle possible - either within a single case or across cases.

Consider first Moore's own proposal for such a measure, viz, that 'the strength of causation [diminishes] in proportion to the number of events through which it is transmitted' (122-3). Recall his approach to accomplice liability. If we grant that causal influence does indeed peter out over time, then we can legitimately judge (ignoring scalarity in the degrees-of-influence sense for now) that a prior-acting accomplice $A$ is less of a cause of the harm (say, the victim's death, $D$ ) than is the principal $P$. If $A$ loads the gun, or lures the victim to a dark alley, or drives $P$ to the venue, and $P$ does the shooting, then $A$ 's act will inevitably be causally upstream of $P$ 's: there are more events between $A$ 's act and $D$ than there are between $P$ 's act and the crime, viz, however many events there are between $A$ 's act and $P$ 's.

So far, so good. But we haven't yet got very far, because so far we only have an ordering ( $A$ is less of a cause of $D$ than is $P$ ) and not a measure ( $A$ causes $D$ to degree $x$, while $P$ causes $D$ to degree $y$ ). And from a legal point of view we really need a measure, for two reasons. First, we need to establish the degree of culpability of $A$ : if, other things being equal, the severity of $A$ 's sentence is to depend on the degree to which he caused $D$, then we need to establish the absolute degree to which he caused $D$, and not merely the fact that $A$ is less of a cause than is $P$.

Second, we need to make consistent judgements across cases. Grant that in the streetcar case the driver's speeding $S$ is too remote from the passenger's harm $H 1$ - in terms of the number of events between $S$ and $H 1$ - for the driver to be legally responsible. But imagine that we are now presented with a second case where the 
same question, whether there are few enough events between some event $E$ and harm $H 2$ for the defendant to count as a proximate cause, arises. Suppose, for example, that $E$ is exposure of a shipyard worker to asbestos and $H 2$ is the worker's suffering from mesothelioma some years later. Consistency of judgement requires that we able to judge whether the causal 'distance' between $E$ and $H 2$ is greater or less than that between $S$ and $H 1$. But since these are two separate cases, we cannot make this judgement (as we could in the accomplice case above) in the absence of a measure of the extent to which causal influence has petered out. (Analogy: I know that Birmingham is a long way from Brisbane, and that Aachen is a long way from Auckland. But unless I have some way of measuring how far Birmingham is from Brisbane, and Aachen from Auckland, I can't know whether the distance from Birmingham to Brisbane is greater or less than the distance between Aachen and Auckland.)

Unfortunately, the prospects for such a measure are bleak, for two main reasons. First, events of different kinds simply cannot be 'counted' in the way that would be required. We can count how many weddings have taken place over a year, or how many times a victim is shot. But we cannot count how many events simpliciter occur between one event $E 1$ and another E2. Events - weddings, say, or birthday parties or wars - have temporal parts. There's the entrance of the bride, the readings, the singing of the hymns, the taking of the vows, the signing of the register, and so on. Each of these smaller events itself has parts - the bride's taking each individual step, the uttering of each word, the singing of each verse of the hymn, and so on. Unless there is some principled stopping point, it's going to turn out that in any period of time between one event and another infinitely many intervening events have elapsed so the idea that causation fades away according to the number of intervening events becomes meaningless.

Second, even if a measure could be devised, it would have a dramatic - and presumably unwelcome - effect on the legitimacy of existing legal judgements. Consider the issues of reparation and land rights. In the late 1980s, the US government paid reparations to Japanese Americans and to Japanese residents - or in some cases their descendants - who were interned during the Second World War. So that looks like a legally recognised 40-odd-year preservation of transitivity. The influence of the violation of land rights is typically taken to persist over even greater periods of time. In New Zealand, the Treaty of Waitangi Act (1975) tasks a tribunal 
with investigating claims by Maoris that they have been prejudicially affected by government policies or practices that are inconsistent with the principles of the Waitangi Treaty. The Act explicitly states that prejudicial effects can result from policies and practices that have been enacted at any time since the Treaty came into effect in 1840. That's preservation of causal influence over a 170-year period.

The point here is that no measure of the extent of petering-out will be consistent both with the claim that causal influence can extend over a period of 170 years, and with the claim that it can peter out sufficiently over, say, a period of an hour to render the streetcar driver's speeding as a non-proximate cause of the injury. So any account that could deliver the required measure would necessarily be massively revisionary from a legal perspective.

Let's turn now to the second dimension of scalarity that Moore endorses: degrees of influence. By contrast with the case of limited transitivity, where he offers (unsuccessfully, I have argued) a way to measure the extent of causation via numbers of intermediate events, here he offers us no candidate for measurement at all. His preferred account of causation is 'singularist', in the sense that causal relations do not reduce to causal laws, though he is neutral about whether causal relations nonetheless reduce to something else (conserved quantities, say, or energy transfer, or transfer of tropes - but not counterfactual dependence) or whether causation is a primitive relation. And he says that according to 'a scalar primitivism or a quantitative reductionist singularism ... some co-present causes can be much smaller than others'; hence his account 'can handle [the problem of scalarity] easily' (508). But how, exactly, is the problem to be handled? Moore, unfortunately, does not say.

It should be fairly obvious that the reductionist options Moore leaves on the table do not do the job: it is very hard to see how the transfer of conserved quantities (such as energy or momentum) or tropes could be pressed into service here. Punching someone really hard transfers more energy to them than does stabbing them gently with a very sharp knife, but the former is not thereby more of a cause of their death than the latter. Nor can we measure the relative degrees of influence by comparing blood loss, since a killer punch may not result in any blood loss at all.

What about the primitivist option? Well, the thought here might be that according to the primitivist position, there just is a fact of the matter, in any given case, about the degree to which each of several simultaneous causes influence their joint effect, and this is not determined by anything else because causation (and its 
scalar nature) is just a fundamental feature of reality. But such a position would be epistemically disastrous, and especially so in a legal context; indeed Moore himself notes that primitivism has long been regarded as unacceptably uninformative in legal circles (505-6). Imagine a dispute about which of two accomplices bears the greater causal responsibility for a crime. How is it to be resolved? In the absence of any story about how degree of influence is to be measured, we have no way, even in principle, of resolving such a dispute, except simply by appealing to our own intuitions about which is the bigger cause. But clearly this is no help when intuitions differ from person to person - as they frequently will in legal contexts - unless we have some way of identifying 'experts' whose intuitions are more reliable; and, given primitivism, this is something we cannot do. (Who would the experts be - judges? Physicists? Philosophers? - and why?)

The upshot is that when it comes to scalarity, Moore does not succeed in putting the law's presuppositions about causation on a sound metaphysical footing. I argued earlier that in the case of limited transitivity, the prospects for any metaphysical account that puts a measure on 'petering out' are bleak, given the lack of consistency across cases enshrined in both common-sense intuitions and legal judgements. In the case of degrees of influence, however, the prospects are somewhat brighter, in that there are some accounts that do permit causation to come in degrees, for example Lewis 2000 and Braham and van Hees 2009. Indeed the latter is explicitly designed in order to provide a measure for legal apportionment. A discussion of the prospects of such accounts for doing the job Moore needs to be done lies outside the scope of this paper. My point, however, is that merely asserting that causation is scalar, by endorsing 'a scalar primitivism or a quantitative reductionist singularism', does not, just by itself, do the job.

\section{References}

Braham, M. \& van Hees, M. (2009), 'Degrees of causation', Erkenntnis, 71: 323-44. Lewis, D. K. (2000), 'Causation as influence', The Journal of Philosophy, 97: 182-97. 